\title{
Pharmacokinetics of Intravenous Glycyrrhizin After Single and Multiple Doses in Patients with Chronic Hepatitis C Infection
}

\author{
Tekla G.J. van Rossum, MD, ${ }^{1}$ Arnold G. Vulto, PhD, ${ }^{2}$ \\ Wim C.J. Hop, MSc, PhD, ${ }^{3}$ and Solko W. Schalm, MD, PhD \\ Departments of 'Hepatogastroenterology, ${ }^{2}$ Pharmacy, and ${ }^{3}$ Biostatistics, Erasmus \\ University Hospital Rotterdam, Rotterdam, The Netherlands
}

\begin{abstract}
Intravenous glycyrrhizin has been used in Japan for the treatment of chronic hepatitis for $>20$ years, although only a few reports of its pharmacokinetic profile atter multiple intravenous doses in small numbers of Japanese patients have been published. The present study compared these Japanese data against the pharmacokinetic characteristics of glycyrrhizin after single and multiple intravenous doses in $35 \mathrm{Eu}$ ropean patients with chronic hepatitis $\mathrm{C}$ infection. We administered 80,160 , or 240 mg glycyrrhizin 3 times/wk or $200 \mathrm{mg}$ glycyrrhizin 6 times/wk for 4 wecks. Twenty-four-hour pharmacokinetic assessments were performed on day $l$ and on or around day 14. Glycyrrhizin levels were determined by high-performance liquid chromatography. The mean ( \pm SD) volume of distribution at steady state on day
\end{abstract}

Accepted for publication September 22, 1999. Printed in the USA

Reproduction in whole or part is not permitted.
1 in the 80-, 160-, 200-, and 240-mg groups were $67 \pm 11,62 \pm 13,54 \pm 7$, and $66 \pm 8$ $\mathrm{mL} / \mathrm{kg}$, respectively. The respective terminal elimination half-lives on day 1 were $7.7 \pm 2.8,10.1 \pm 1.4,9.0 \pm 2.3$, and $8.6 \pm$ 2.1 hours. The area under the curve (AUC) increased linearly with doses $\leq 200 \mathrm{mg}$ $(r=0.67 ; P<0.001)$. No significant differences between day 1 and day 14 were found in any dose group, with the exception of AUC in the $200-\mathrm{mg}$ group, which was significantly higher on day 14 compared with day $1(P=0.03)$. Comparing the European and Japanese data, the mean ( \pm SD) AUC was $289 \pm 244 \mu \mathrm{g} / \mathrm{h}$ per $\mathrm{mL}$ for the former and $402 \pm 372 \mu \mathrm{g} / \mathrm{h} \mathrm{per} \mathrm{mL}$ for the latter; the half-life was $8.2 \pm 2.6$ versus $8.8 \pm 9.0$ hours; and the total clearance was $7.6 \pm 3.6$ versus $8.5 \pm 5.7 \mathrm{~mL} / \mathrm{h}$ per $\mathrm{kg}$. Thus our pharmacokinetic data are comparable to those from Japan. Glycyrrhizin's pharmacokinetics are linear up to $200 \mathrm{mg}$. Drug accumulation is seen after 2 weeks of treatment with $200 \mathrm{mg}$ administered 6 times/wk. Key words: pharmacokinetics, glycyrrhizin, hepatitis C. 
T.G.J. VAN ROSSUM ET AL.

\section{INTRODUCTION}

Glycyrrhizin, extracted from the roots of the plant Glycyrrhiza glabra (licorice), has been used as a treatment for chronic hepatitis in Japan for more than 20 years. ${ }^{1}$ According to information from the manufacturer, Minophagen Pharmaceutical Co., Ltd. (Tokyo, Japan), tens of millions of ampoules of Stronger Neo-Minophagen $C^{\circledR}$ (SNMC) containing $2 \mathrm{mg}$ of glycyrrhizin per $\mathrm{mL}$ are used annually for this indication in Japan.

Glycyrrhizin is a conjugate of 1 molecule of glycyrrhetinic acid and 2 molecules of glucuronic acid (Figure 1). Suzuki et $\mathrm{al}^{2,3}$ reported that intravenously administered glycyrrhizin lowered serum transaminase levels significantly in patients with chronic hepatitis. Arase et $\mathrm{al}^{4}$ reported that in Japanese patients with chronic hepatitis $\mathrm{C}$ infection, normalization of alanine aminotransferase (ALT) induced by long-term glycyrrhizin treatment prevented development of hepatocellular carcinoma.

Intravenously administered glycyrrhizin is metabolized in the liver by lysosomal $\beta$-D-glucuronidase to 3-mono-glucuronide- glycyrrhetinic acid. The metabolite is excreted with bile into the intestine, where it is metabolized by hacteria into glycyrrhetinic acid, which can be reabsorbed (see Figure 1). 5

A MEDLINE ${ }^{\circledR}$ search of the literature from January 1966 to July 1999 using the key words glycyrrhizin(e) and pharmacokinetics yielded a small number of Japanese studies involving $\leq 10$ patients. These studies $^{6-9}$ described the pharmacokinetic profile of glycyrrhizin after multiple doses of a single dose strength in patients with acute and chronic hepatitis and cirrhosis of different causes. In these patients, total body clearance was inversely correlated with serum ALT level $(r=-0.7$; $P<0.05$ ), suggesting a correlation of pharmacokinetic variables with hepatic function.

We conducted a Phase I/II clinical trial in Europe to evaluate the dose-dependent pharmacokinetics, safety, and efficacy of glycyrrhizin treatment. The safety and efficacy results have been reported elsewhere. ${ }^{10}$ The study reported here was performed to compare the Japanese data with the pharmacokinetics of increasing doses of glycyrrhizin in European patients.

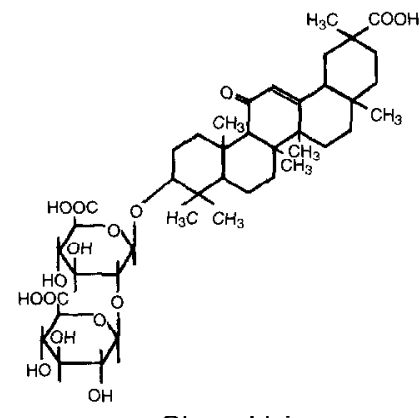

Glycyrrhizin

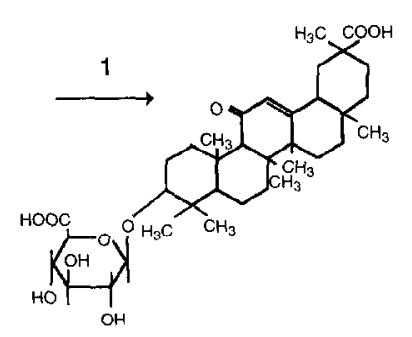

18-beta-glycyrrhetinic acid mono-beta-D-glucuronide

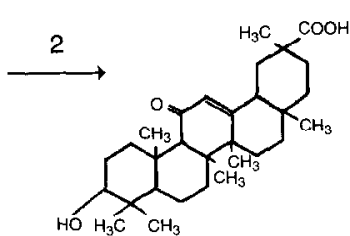

18-beta-glycyrrhetinic acid

Figure 1. Metabolism of glycyrrhizin after intravenous administration: (1) in the liver, by lysosomal $\beta$-D-glucuronidase, and ( 2 ) in the intestine, by bacterial $\beta$-D-glucuronidase. 


\section{PATIENTS AND METHODS}

Only patients with chronic hepatitis $C$ infection, with a positive hepatitis $\mathrm{C}$ virus RNA titer, serum AI $T \geq 1.5$ times the upper limit of normal (ULN), and findings on liver biopsy consistent with mild to moderate liver fibrosis or cirrhosis were included. Patients were not eligible for inclusion if they had other causes of liver disease, decompensated cirrhosis (Child-Pugh score $>7$ ), or hepatocellular carcinoma.

The study was conducted according to the Declaration of Helsinki and good clinical practice guidelines. The protocol was approved by the medical ethical committee of the Erasmus University Hospital Rotterdam, and all patients gave their written informed consent.

\section{Study Treatment}

Glycyrrhizin was given as SNMC, a clear solution for intravenous use, consisting of $2 \mathrm{mg}$ glycyrrhizin, $1 \mathrm{mg}$ cysteine, and $20 \mathrm{mg}$ glycine per $\mathrm{mL}$ in physiologic saline solution. Patients received 80,160 , or $240 \mathrm{mg}$ intravenous glycyrrhizin 3 times/wk or $200 \mathrm{mg}$ intravenous glycyrrhizin 6 times/wk for 4 weeks.

The medication administered 3 times/ wk was given by drip infusion over 15 to 20 minutes in a total volume of $220 \mathrm{~mL}$. The infusion line was then flushed with $25 \mathrm{~mL}$ sodium chloride $(0.9 \%)$. The medication given 6 times/wk was administered undiluted into a peripheral vein over 3 to 5 minutes.

\section{Pharmacokinetic Measurements}

Pharmacokinetic measurements were obtained on the first day of treatment and on or around day 14. Patients were not allowed to consume food or drink (except water) after $11 \mathrm{PM}$ of the night before pharmacokinetic measurements were to be taken. On the days of pharmacokinetic measurements, food was allowed 4 hours after administration of medication, and water was allowed as required. Patients remained semirecumbent from 0.5 hour before until 4 hours after receiving medication.

\section{Blood Sampling}

An indwelling cannula was placed in 1 arm for blood sampling; medication was administered in the other arm. Before sampling, $\sim 1 \mathrm{~mL}$ of blood was discarded. Ethylenediaminetetraacetic acid-blood samples ( $7 \mathrm{~mL}$ ) were collected at the following times on the days of pharmacokinetic measurements: before administration of medication and at $0,5,15,45,60,90$ minutes and 2, 4, $6,8,10,12,16,18$, and 24 hours after administration of medication (administration of medication was complete at time 0 ). Samples were stored on ice, and plasma was separated within 1 hour by centrifugation at $4^{\circ} \mathrm{C}$ and $3000 \mathrm{~g}$ for 10 minutes. Plasma samples were stored at $-20^{\circ} \mathrm{C}$ until analyzed.

\section{High-Performance Liquid Chromatography}

Plasma samples were analyzed by a validated high-performance liquid chromatographic (HPLC) method modified from Raggi et al. ${ }^{11}$ Fifty $\mu \mathrm{L}$ propylparaben (25 $\mathrm{mg} / \mathrm{L}$ internal standard solution) and $2 \mathrm{~mL}$ methanol were added to $500 \mu \mathrm{L}$ plasma. After mixing and centrifugation, the supernatant was decanted into another test tube and evaporated at $40^{\circ} \mathrm{C}$ with flushing nitrogen. The residue was dissolved in $500 \mu \mathrm{L}$ acetonitrile/citrate (180:320) buffer 
(0.1 mol/L, $\mathrm{pH} \mathrm{2.8).} \mathrm{After} \mathrm{vortexing} \mathrm{and}$ centrifugation, $20 \mu \mathrm{L}$ of the supernatant was injected into the HPLC system. The extract was separated on a ChromSpher-5 C8 (Chrompack, Bergen op Zoom, The Netherlands) column $(200 \times 3 \mathrm{~mm} ; 5 \mu \mathrm{m}$ particles) with the acetonitrile/citrate buffer at a flow of $0.6 \mathrm{~mL} / \mathrm{min}$ at ambient temperatures. Detection was by ultraviolet absorption at $250 \mathrm{~nm}$ with a diode array detector.

As validated in our laboratory, the assay was linear over a range from $\geq 0.5$ to $150 \mathrm{mg} / \mathrm{L}$. The limit of quantification was $0.5 \mathrm{mg} / \mathrm{L}$. Day-to-day variations were $<2 \%$ at concentrations of $>30 \mathrm{mg} / \mathrm{L}$ and $<5 \%$ in the lower range $(\sim 1 \mathrm{mg} / \mathrm{L})$.

\section{Pharmacokinetic Analysis}

A weighted least-squares regression analysis, with $1 / y^{2}$ as a weighting factor for each data point, was performed using Topfit version $2.0^{12}$ to analyze the plasma concentration-time data for each patient. We calculated the maximum concentration $\left(\mathrm{C}_{\max }\right)$, total clearance $\left(\mathrm{Cl}_{\text {tot }}\right)$, volume of distribution at steady state $\left(\mathrm{V}_{\mathrm{ss}}\right)$, area under the curve (AUC) from time zero to infinity, and terminal elimination half-life $\left(t_{1 / 2}\right)$.

Data analysis was based on a weighted 3-compartment disposition model, which was deemed the most appropriate model based on visual inspection and minimized residuals.

\section{Statistical Analysis}

Statistical analysis was performed using Stata 5.0 software (Stata Corporation, College Station, Texas). Results are expressed as mean $\pm \mathrm{SD}$. Comparisons between groups were conducted using the Kruskal-Wallis test; if $P<0.05$, the Mann-
Whitney test was used to perform further pairwise comparisons between groups. Differences within groups were assessed using the Wilcoxon signed rank test. Spearman correlation coefficients were used. Significance was set at $P=0.05$ (2-sided) for all tests.

\section{RESULTS}

The baseline characteristics of the patients are shown in Table $\mathrm{I}$. The 4 groups were comparable in terms of all characteristics except baseline ALT value, which was significantly lower in the group receiving $240 \mathrm{mg} 3$ times/wk than in the group receiving $200 \mathrm{mg} 6$ times/wk ( $P=0.02)$.

Figure 2 shows a chromatogram 6 hours after a single dose of $200 \mathrm{mg}$ glycyrrhizin. Figure 3 shows the mean course of the measured plasma concentration on day 1 and day 14 for the group receiving 200 mg glycyrrhizin 6 times/wk. The plasma concentration of glycyrrhizin declined according to a 3-compartment model.

The second of the 2 pharmacokinetic measurements was performed on day 13 in 1 patient; day 14 in 27 patients; day 15 in 2 patients; and day 16 in 3 patients. Results for the pharmacokinetic variables are shown in Table II. A dose-response relationship was found between the $\mathrm{C}_{\max }$ and AUC. The $\mathrm{C}_{\max }$ increased in a log-log plot with increasing dosage (day $1, r=0.82$, $P<0.001$; day $14, r=0.89, P<0.01$ ), whereas therc was no significant deviation from linearity. A linear increase in AUC with dose was found only for the 80-, 160-, and 200-mg doses (day 1, $r=0.67$, $P<0.001$; day 14, $r=0.57, P<0.002$ ). The mean $( \pm S D) V_{s s}$ on day 1 was between $54 \pm 7$ and $67 \pm 11 \mathrm{~mL} / \mathrm{kg}$; the mean $\mathrm{Cl}_{\text {tot }}$ was between $5.9 \pm 2.5$ and $10.3 \pm 3.1$ $\mathrm{mL} / \mathrm{h}$ per $\mathrm{kg}$; and the mean $\mathrm{t}_{1 / 2}$ was be- 
CLINICAL THERAPEUTICS

Table I. Baseline characteristics of the 35 patients, by glycyrrhizin dose.

\begin{tabular}{|c|c|c|c|c|}
\hline & \multicolumn{4}{|c|}{ Dose, mg (No. of Patients) } \\
\hline & $80(8)$ & $160(7)$ & $240(7)$ & $200(13)$ \\
\hline $\begin{array}{l}\text { Frequency of } \\
\text { administration } \\
\text { Sex }\end{array}$ & 3 times/wk & 3 times/wk & 3 times/wk & 6 times/wk \\
\hline Malc & 6 & 5 & 7 & 11 \\
\hline Female & 2 & 2 & 0 & 2 \\
\hline \multicolumn{5}{|l|}{ Age (y) } \\
\hline Mean & 47 & 54 & 43 & 50 \\
\hline Range & $35-66$ & $43-60$ & $34-59$ & $39-70$ \\
\hline \multicolumn{5}{|l|}{ Weight $(\mathrm{kg})$} \\
\hline Mean & 71 & 78 & 79 & 79 \\
\hline Range & $55-107$ & $64-94$ & $62-119$ & $63-109$ \\
\hline Cirrhosis & 3 & 3 & 3 & 7 \\
\hline No cirrhosis & 5 & 4 & 4 & 6 \\
\hline \multicolumn{5}{|l|}{ ALT (ULN) } \\
\hline Mean & 3.8 & 3.6 & $2.1^{*}$ & 3.9 \\
\hline $95 \% \mathrm{CI}$ & $2.0-5.7$ & $2.0-5.1$ & $1.8-2.5$ & $2.2-5.7$ \\
\hline
\end{tabular}

$\mathrm{ALT}=$ alanine aminotransterase; $\mathrm{ULN}=$ upper limit of normal.

${ }^{*}$ Significantly $<200 \mathrm{mg} 6$ times $/ \mathrm{wk} ; P=0.02$.

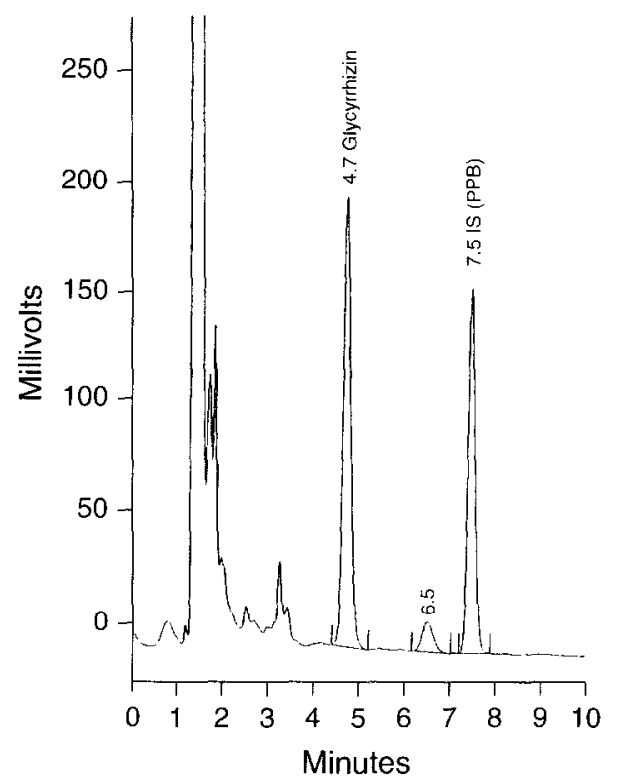

Figure 2. Chromatogram of a plasma sample obtained 6 hours after a single dose of 200 mg glycyrrhizin. IS = internal standard; PPB = propylparaben. 
T.G.J. VAN ROSSUM ET AL.

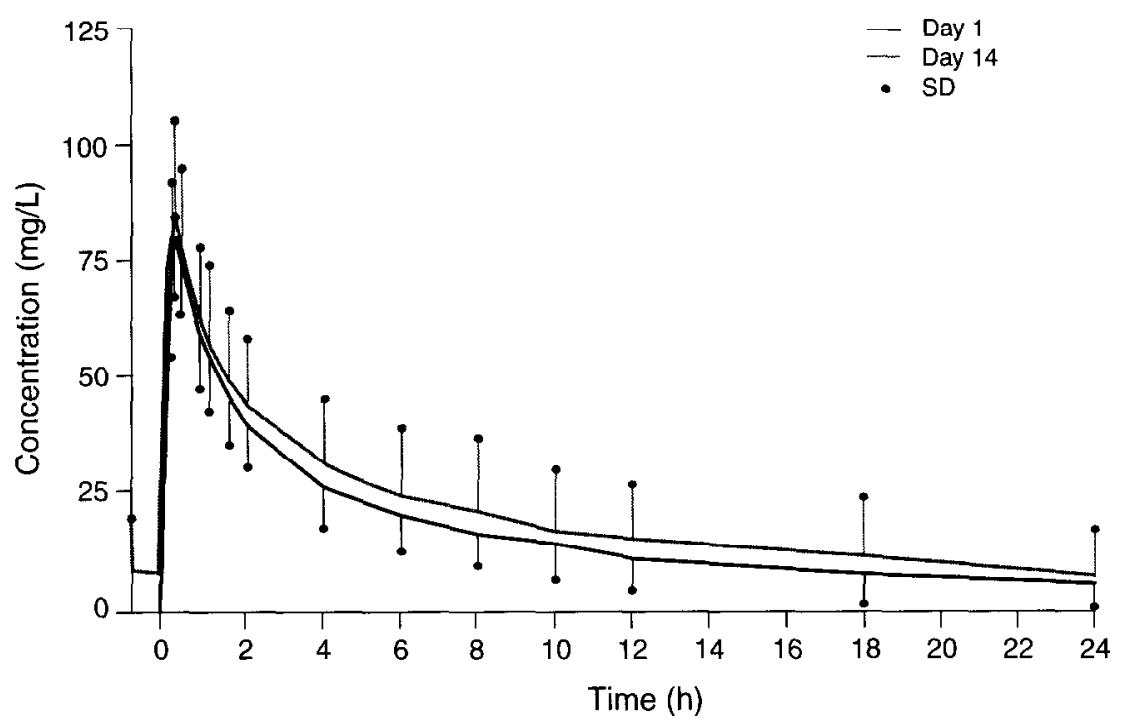

Figure 3. Mean measured plasma concentration-time profile for the group administered $200 \mathrm{mg}$ glycyrrhizin on day 1 and day 14.

tween $7.7 \pm 2.8$ and $10.1 \pm 1.4$ hours. No significant difference was noted on day 1 and day 14 between dose groups, except for the significantly higher AUC in the 200mg group on day 14 compared with day 1 $(P=0.03)$. All variables showed a strong correlation between day 1 and day 14 .

Table III shows the $\mathrm{Cl}_{\text {tot }}$ and $\mathrm{t}_{1 / 2}$ for cirrhotic and noncirrhotic patients on day 1 and day 14 after combining all dose groups. There were no significant differences between cirrhotic and noncirrhotic patients. No correlation could be found between ALT levels at baseline and $\mathrm{Cl}_{\text {tot }}$ or $\mathrm{t}_{1 / 2}$.

\section{DISCUSSION}

This study reports the pharmacokinetic characteristics of increasing doses of intravenous glycyrrhizin after single and multi- ple doses in the largest cohort of patients (35 patients) studied to date. The variation in $\mathrm{C}_{\max }$ in the $200-\mathrm{mg}$ group appeared to be substantially larger than in the other 3 groups (Figure 4). An explanation for this observation could be that the 200-mg dose was administered by manual direct intravenous injection in 3 to 5 minutes whilc the other 3 dosages were administered by drip infusion in 15 to 20 minutes; it is likely that the slower infusion rate caused a more equal administration of glycyrrhizin between patients than injection.

It is possible that different rates of infusion might affect the dose linearity and number of compartments. However, in our study, the AUC increased linearly with dose hetween 80 to $200 \mathrm{mg}$, although the 80 and 160-mg doses were administered over 15 to 20 minutes, and the $200-\mathrm{mg}$ dose was 


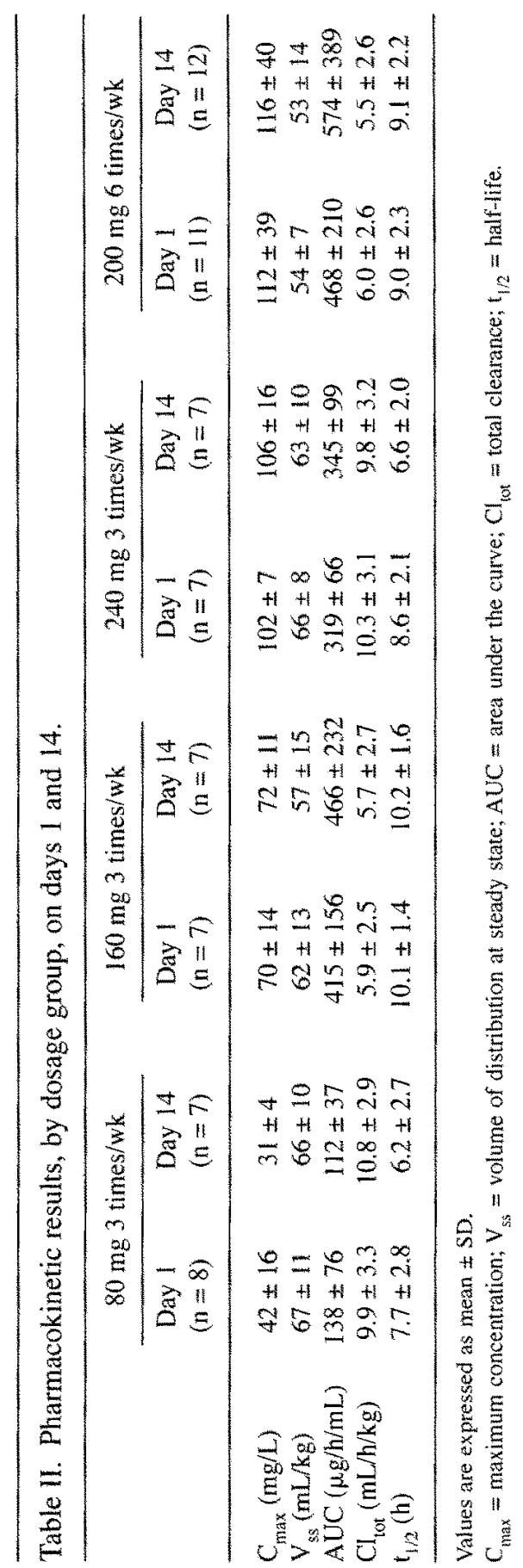


T.G.J. VAN ROSSUM ET AL.

Table III. Total clearance $\left(\mathrm{Cl}_{\text {tot }}\right)$ and half-life $\left(\mathrm{t}_{1 / 2}\right)$ for patients with chronic hepatitis and cirrhosis on days 1 and 14 .

\begin{tabular}{lccccc}
\hline & \multicolumn{2}{c}{ Chronic Hepatitis } & & \multicolumn{2}{c}{ Cirrhosis } \\
\cline { 2 - 3 } \cline { 6 - 6 } & $\begin{array}{c}\text { Day 1 } \\
(\mathrm{n}=19)\end{array}$ & $\begin{array}{c}\text { Day 14 } \\
(\mathrm{n}=17)\end{array}$ & & $\begin{array}{c}\text { Day 1 } \\
(\mathrm{n}=14)\end{array}$ & $\begin{array}{c}\text { Day 14 } \\
(\mathrm{n}=16)\end{array}$ \\
\hline $\mathrm{Cl}_{\mathrm{tot}}(\mathrm{mL} / \mathrm{h} / \mathrm{kg})$ & $8.3 \pm 3.0$ & $8.1 \pm 3.2$ & & $7.2 \pm 4.0$ & $7.1 \pm 4.0$ \\
$\mathrm{t}_{1 / 2}(\mathrm{~h})$ & $8.2 \pm 2.2$ & $7.7 \pm 2.5$ & & $9.7 \pm 2.3$ & $8.7 \pm 2.7$ \\
\hline
\end{tabular}

Results are expressed as mean $\pm \mathrm{SD}$.

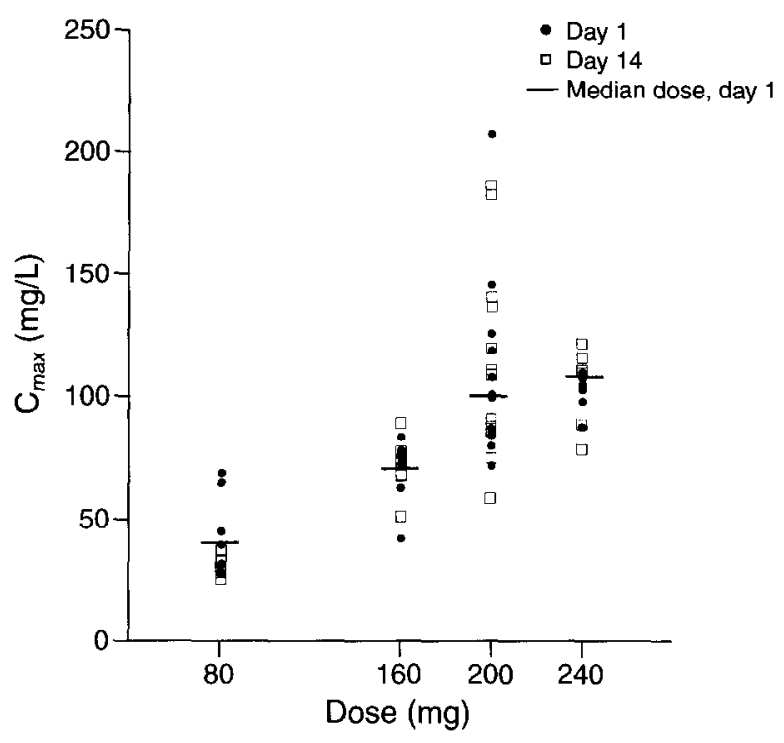

Figure 4. Calculated maximum concentration $\left(C_{\max }\right)$ per patient per dose on day 1 and day 14.

given over 3 to 5 minutes. The pharmacokinctic data after both administration rates fitted best according to a 3-compartment model. So the difference between administration over 3 to 5 minutes or 15 to 20 minutes does not appear to affect dose linearity or compartmentalization.

With glycyrrhizin's half-life of $\sim 9$ hours, a dosing interval of 24 hours might lead to some accumulation. Indeed, the AUC for the group receiving $200 \mathrm{mg} 6$ times/wk was significantly higher at day 14 compared with day 1; after 14 days of treatment, the mean $( \pm \mathrm{SD})$ glycyrrhizin concentration before administration of medication was $7.8 \pm$ $11.0 \mathrm{mg} / \mathrm{L}$.

Our pharmacokinetic data are based on samples taken between 0 minutes and 24 hours after administration of medication. We observed a 3-compartment distribu- 
tion over the entire period. Tanaka et $a^{6}$ investigated the pharmacokinetic profile of multiple doses of intravenously administered glycyrrhizin $120 \mathrm{mg}$ in 8 patients with chronic hepatitis of unreported cause, and Yamamura et $\mathrm{al}^{7}$ investigated the same regimen in 4 patients with acute hepatitis and 6 patients with cirrhosis ( 5 of 6 cases were caused by chronic hepatitis $\mathrm{C}$ infection). In these studies, samples were taken between 2 and 10 hours after drug administration. Over this 8 -hour period, the investigators observed a monoexponential decline in glycyrrhizin, as in our study.

Combining the pharmacokinetic data on the 8 patients from Tanaka et $\mathrm{al}^{6}$ and the 10 patients from Yamamura et $\mathrm{al}^{7}$ yields a mean $( \pm \mathrm{SD}) \mathrm{t}_{1 / 2}$ of $8.8 \pm 9.0$ hours, a $\mathrm{Cl}_{\text {tot }}$ of $8.5 \pm 5.7 \mathrm{~mL} / \mathrm{h} \mathrm{per} \mathrm{kg}$, and an AUC of $402 \pm 372 \mu \mathrm{g} / \mathrm{h}$ per $\mathrm{mL}$. These data obtained after multiple doses of glycyrrhizin are comparable to those obtained in our study (Table IV).

The $t_{1 / 2}$ of glycyrrhizin in 3 healthy volunteers has been reported as 3.5 hours. ${ }^{13,14}$ Yamamura et $\mathrm{al}^{13}$ observed an increase in $\mathrm{t}_{1 / 2}$ and a decrease in $\mathrm{Cl}_{\text {tot }}$ among cirrhotic patients compared with noncirrhotic patients. We found no significant differences between cirrhotic and noncirrhotic patients (Table III). $\mathrm{Cl}_{\text {tot }}$ and $\mathrm{t}_{1 / 2}$ are pharmacokinetic parameters that depend on physiologic variables. Therefore it seems logical that a decrease in hepatic function would lead to a decrease in $\mathrm{Cl}_{\text {tor }}$ and an increase in $t_{1 / 2}$. We did not observe such a relationship in the present study, probably because patients with severe liver disease were excluded. Mean ALT levels before the initiation of treatment in the Japanese patients were $\sim 300 \mathrm{IU} / \mathrm{L}$, much higher than our baseline ALT levels of $\sim 3.5$ times the ULN, or $150 \mathrm{IU} / \mathrm{L}$.

Comparisons of pharmacokinetic data between centers should be interpreted cautiously. Variations in population, degree of disease, dose rate and regimen, sampling frequency, and duration of observation are all capable of influencing study results. Given these limitations, we conclude that our data corroborate and strengthen those from the smaller studies. ${ }^{6.7}$

The first phase of the 3-compartment model can be explained predominantly by the distribution of glycyrrhizin. The $\mathrm{V}_{\mathrm{ss}}$ was $\sim 4.5 \mathrm{~L} /$ patient, which means that glycyrrhizin was confined mainly to the vascular compartment. Glycyrrhizin is not taken up in blood cells. ${ }^{13}$ The second phase can be explained by elimination, predominantly through the metabolism of glycyrrhizin to 3-mono-glucuronideglycyrrhetinic acid in the liver by lysosomal $\beta$-D-glucuronidase. ${ }^{5}$ The third phase

Table IV. Japanese and European pharmacokinetic data after multiple doses.

\begin{tabular}{lcc}
\hline & $\begin{array}{c}\text { Japan } \\
(\mathrm{N}=18)\end{array}$ & $\begin{array}{c}\text { Europe } \\
(\mathrm{N}=33)\end{array}$ \\
\hline $\mathrm{AUC}$ for $120 \mathrm{mg}(\mu \mathrm{g} / \mathrm{h} / \mathrm{mL})$ & $402 \pm 372$ & $289 \pm 244$ \\
$\mathrm{Cl}_{\mathrm{tot}}(\mathrm{mL} / \mathrm{h} / \mathrm{kg})$ & $8.5 \pm 5.7$ & $7.6 \pm 3.6$ \\
$\mathrm{t}_{1 / 2}(\mathrm{~h})$ & $8.8 \pm 9.0$ & $8.2 \pm 2.6$ \\
\hline
\end{tabular}

Results are expressed as mean $\pm \mathrm{SD}$.

$\mathrm{AUC}=$ area under the curve; $\mathrm{Cl}_{\text {tot }}=$ total clearance; $\mathrm{t}_{1 / 2}=$ half-life. 
can be explained by an enterohepatic cycle of glycyrrhizin, which would extend the elimination phase..$^{15,16}$

\section{CONCLUSIONS}

Glycyrrhizin exhibits linear pharmacokinetics up to $200 \mathrm{mg}$; steady-state kinetics are attained after 2 weeks of $200 \mathrm{mg}$ administered 6 times/wk. Our pharmacokinetic data are comparable to the Japanese findings, although we did not find a correlation between hepatic function and pharmacokinetics. This difference may be explained by our patients having milder liver disease.

\section{ACKNOWLEDGMENTS}

This study was supported by Minophagen Co., Ltd., Tokyo, Japan.

The authors gratefully acknowledge the contributions of F. van Vliet, who assessed all pharmacokinetic samples; L.M. Hanff, hospital pharmacist, and her staff, for distributing the study medication; and K. Groen, PhD (Kinesis, Breda, The Netherlands), for his advice with regard to the interpretation of the pharmacokinetic data.

Address correspondence to: Solko W. Schalm, MD, PhD, Department of Hepatogastroenterology, Erasmus University Hospital Rotterdam, PO Box 2040, 3000 CA Rotterdam, The Netherlands.

\section{REFERENCES}

1. Fujisawa K, Tandon BN. Therapeutic approach to the chronic active liver disease: Summary of a satellite symposium. In: Nishioka K, Suzuki H, Mishiro S, Oda T, eds. Viral Hepatitis and Liver Disease. Tokyo: Springer-Verlag; 1994:662-665.
2. Suzuki H, Ohta $Y$, Takino T, et al. The therapeutic effects of Stronger Neo Minophagen $\mathrm{C}$ for chronic hepatitis. Igaku no Ayumi. 1977;102:562-568.

3. Suzuki H, Ohta Y, Takino T, et al. Effects of glycyrrhizin on biochemical tests in paticnts with chronic hepatitis. Asian Med J. $1983 ; 26: 423-438$.

4. Arase $Y$, Ikeda K, Murashima N, et al. The long term efficacy of glycyrrhizin in chronic hepatitis $\mathrm{C}$ patients. Cancer. 1997:79:1494-1500.

5. Akao T, Akao T, Hattori M, et al. Hydrolysis of glycyrrhizin to $18 \beta$-glycyrrhetyl monoglucuronide by lysosomal $\beta$-d-glucuronidase of animal livers. Biochem Pharmacol. 1991;41:1025-1029.

6. Tanaka N, Yamamura Y, Santa T, et al. Pharmacokinetic profiles of glycyrrhizin in patients with chronic hepatitis. Biopharm Drug Dispos. 1993;14:609-614.

7. Yamamura Y, Tanaka N, Santa T, et al. The relationship between pharmacokinetic behaviour of glycyrrhizin and hepatic function in patients with acute hepatitis and liver cirrhosis. Biopharm Drug Dispos. 1995; 16:13-21.

8. Takahashi M, Nakano S, Takeda I, et al. The pharmacokinetics of the glycyrrhizin and glycyrrhetinic acid after intravenous administration of glycyrrhizin for the patients with chronic disease caused by type C hepatitis virus. Nippon Shokakibyo Gakkai Zasshi. 1995;12:1926-1936.

9. Yamamura Y, Kotaki H, Tanaka N, et al. The pharmacokinetics of glycyrrhizin and its restorative effect on hepatic function in patients with chronic hepatitis and in chronically carbon-tetrachloride-intoxicated rats. Biopharm Drug Dispos. 1997; 18:717-725. 
CLINICAL THERAPEUTICS $^{8}$

10. TGJ van Rossum, AG Vulto, WCJ Hop, et al. Intravenous glycyrrhizin for the treatment of chronic hepatitis $\mathrm{C}$ : A doubleblind, randomized, placebo-controlled trial. J Gastroenterol Hepatol. 1999;14: 1093-1099.

11. Raggi MA, Bugamelli F, Nobile L, et al. HPLC determination of glycyrrhizin and glycyrrhetic acid in biological fluids, after licorice extract administration to humans and rats. Boll Chim Farm. 1994;133. 704-708

12. Heinzel G, Woloszczak R, Thomann P. Pharmacokinetic and Pharmacodynamic Data Analysis System for the PC. Version 2.0. Stuttgart, Germany: Gustav Fischer Verlag; 1993.

13. Yamamura Y, Kawakami J, Santa T, et al Pharmacokinetic profile of glycyrrhizin in healthy volunteers by a new high-performance liquid chromatographic method. J Pharm Sci. 1992;81:1042-1046.

14. Krähenbühl S, Hasler F, Krapf R. Analysis and pharmacokinetics of glycyrrhizic acid and glycyrrhetinic acid in humans and experimental animals. Steroids. 1994;59:121-126.

15. Ichikawa T, Ishida $S$, Sakiya $Y$, et al. Biliary excretion and enterohepatic cycling of glycyrrhizin in rats. $J$ Pharm Sci. 1986; 75:672-675.

16. Ishida S, Sakiya $Y$, Ichikawa $T$, et al. Prediction of glycyrrhizin disposition in rat and man by a physiologically based pharmacokinetic model. Chem Pharm Bull. I990;38:212-218 